\title{
Nitrogen-Doped Carbon Dots from Averrhoa carambola Fruit Extract as a Fluorescent Probe for Methyl Orange
}

\author{
Muhammad Zulfajri ${ }^{1,2}{ }^{\mathbb{D}}$, Sandhiya Dayalan ${ }^{1}$, Wang-Yu Li ${ }^{1}$, Chia-Jung Chang ${ }^{1}$, \\ Yuan-Pin Chang ${ }^{3}$ and Genin Gary Huang ${ }^{1,4, *(D)}$ \\ 1 Department of Medicinal and Applied Chemistry, Kaohsiung Medical University, Kaohsiung 80708, Taiwan; \\ u106850002@kmu.edu.tw (M.Z.); u107850013@kmu.edu.tw (S.D.); u106021130@kmu.edu.tw (W.-Y.L.); \\ u105550011@kmu.edu.tw (C.-J.C.) \\ 2 Department of Chemistry Education, Universitas Serambi Mekkah, Aceh 23245, Indonesia \\ 3 Department of Chemistry, National Sun Yat-sen University, Kaohsiung 80424, Taiwan; \\ ypchang@mail.nsysu.edu.tw \\ 4 Department of Medical Research, Kaohsiung Medical University Hospital, Kaohsiung 80708, Taiwan \\ * Correspondence: genin@kmu.edu.tw
}

Received: 17 October 2019; Accepted: 15 November 2019; Published: 16 November 2019

check for updates

\begin{abstract}
In this study, a simple and green hydrothermal treatment was performed to prepare nitrogen-doped carbon dots (NCDs) from Averrhoa carambola (AC) fruit extract as a carbon precursor and L-arginine (Arg) as a nitrogen dopant. The AC-NCDs were characterized by UV light, fluorescence spectroscopy, transmission electron microscopy, FTIR spectroscopy, Raman spectroscopy, UV-vis spectroscopy, and zeta potential analyzer. The AC-NCDs were spherical and the average diameter was estimated to be $6.67 \mathrm{~nm}$. The AC-NCDs exhibited the maximum emission intensity at $446 \mathrm{~nm}$ with $360 \mathrm{~nm}$ excitation wavelength. The fluorescence quenching behavior of AC-NCDs after interacting with methyl orange (MO) dye was studied. The interaction of AC-NCDs and MO was achieved within $3 \mathrm{~min}$ and the fluorescence quenching was maintained to a fixed value even after $30 \mathrm{~min}$. The linearity was obtained in the range of 1 to $25 \mu \mathrm{M} \mathrm{MO}$ with a $0.30 \mu \mathrm{M}$ detection limit. Furthermore, the $\mathrm{pH}$ values affected the quenching behavior of the AC-NCDs/MO system where the interaction mechanisms were driven by the electrostatic interaction, $\pi-\pi$ interaction, inner filter effect, and energy transfer. The pH 5 maintained higher quenching efficiency while other $\mathrm{pH}$ values slightly decreased the quenching efficiency. Incoming applications, the AC-NCDs can be used in various important fields, especially for environmental protection.
\end{abstract}

Keywords: Averrhoa carambola; fruit extract; L-arginine; amino acid; nitrogen-doped carbon dots; hydrothermal; methyl orange; fluorescent probe

\section{Introduction}

Recently, carbon dots (CDs) exhibiting strong fluorescent properties with excitation-dependent emissions have arrested much attention [1]. CDs are superior in their unique properties such as good water solubility, low toxicity, high photostability, good biocompatibility, excellent optical properties, good electrical conductivity, and easy functionalization or modification [2]. Several parameters, including reaction time, reaction temperature, particle size, dopant nature, carbon precursor amount, $\mathrm{pH}$ value, and solvent present a key role in increasing fluorescent properties of CDs which can be utilized as the chemical sensor, biosensor, bio-imaging, catalyst, drug carrier, and energy storage device [3-5]. To increase the fluorescent properties, the dopants of boron (B), nitrogen (N), sulfur 
(S), and phosphor (P) were commonly added to functionalize CDs [4]. Among these heteroatoms, $\mathrm{N}$-dopant is a widely used dopant to increase the fluorescent properties of CDs.

Nowadays, the chemistry concepts of economical and green materials attract much attention to the synthesis of CDs. Cheap and available natural resources are still challengeable as the carbon precursors to produce CDs [6]. Various top-down and bottom-up synthesis methods have been promoted to produce $\mathrm{CDs}$ including hydrothermal, microwave, ultrasonic, laser ablation, electrochemical oxidation, and chemical oxidation treatments [7]. However, the hydrothermal treatment is widely used as a green, straightforward, affordable and soft chemical route method by using natural resources for the production of CDs which results in uniform particle sizes [8,9]. Averrhoa carambola (AC), one of the natural resources, is often known as "star fruit" from the family of Oxalidaceae and widely planted in India, China, and Southeast Asia [10,11]. AC fruit is globally marketed due to its pharmacological significances including analgesic, hypotensive, hypocholesterolemic, hypolipidemic, antitumor antimicrobial, antifungal, anti-ulcer, and antioxidant activities [11]. The main constituents in the crude AC fruit extract are saponins, alkaloids, flavonoids, tannins, proanthocyanidins, epicatechin, gallic acid, L-ascorbic acid, sterols, fatty acids, sugars, minerals, volatile favors, dietary fibers, pectin, cellulose, hemicellulose, carotenoid, carbohydrates, proteins, calories, fats, carotene, tartaric acid, oxalic acid, $\alpha$-ketoglutaric acid, and citric acid [12]. In this study, the AC fruit extract has been chosen as a carbon precursor for the production of CDs. Besides, amino acids can be used to produce heteroatom-doped CDs with increased fluorescent properties that undergo dehydration and decarboxylation reactions in the synthesis process [13]. L-arginine (Arg), an amino acid, has been chosen as N-dopant to react with the primary carbon precursor (AC fruit extract) which has $\mathrm{N}$ content approximately $32 \%$ [14].

On the other hand, organic dyes (ODs) are widely used in food, pharmaceutical, plastic, cosmetic, paper, rubber, textile, and leather industries [15]. The leftover of ODs is considered a wide variety of pollutants in the natural water resources or wastewater treatment systems. Their release into water can render environmental pollution because the ODs are commonly toxic and carcinogenic for human health [16]. Thus, the probing of ODs is of high significance. Methyl orange (MO), one of the ODs, is a variety of p-aminoazobenzene dyes and widely used in the textile industry and chemical laboratory as an acid-base indicator [17]. But, the MO solution is toxic and irritating for human. So far, there are very few reports about the detection methods of $\mathrm{MO}$ [18-21]. Therefore, it is needed to promote facile, simple, and efficient methods. Toward this objective, a facile and green hydrothermal treatment was adopted to synthesize AC-nitrogen-doped carbon dots (AC-NCDs) from AC fruit extract and Arg. The physicochemical and optical properties of AC-NCDs were characterized. The fluorescence behavior of AC-NCDs after interacting with MO was also evaluated. Thus, AC-NCDs can be used as a higher selective and sensitive fluorescent probe to detect MO. The schematic representation of the synthesis and application of AC-NCDs as a fluorescent probe for MO was demonstrated in Figure 1. Comparing to the direct measurements by UV-vis spectrometry or fluorescence spectrophotometer, the proposed AC-NCDs fluorescent probe for MO provides the advantage of better selectivity and free from several spectral interferences. As far as we know, there is no other report on the production of NCDs utilizing AC fruit extract with Arg. The use of other NCDs as fluorescent probes for MO detection has also not been declared. 


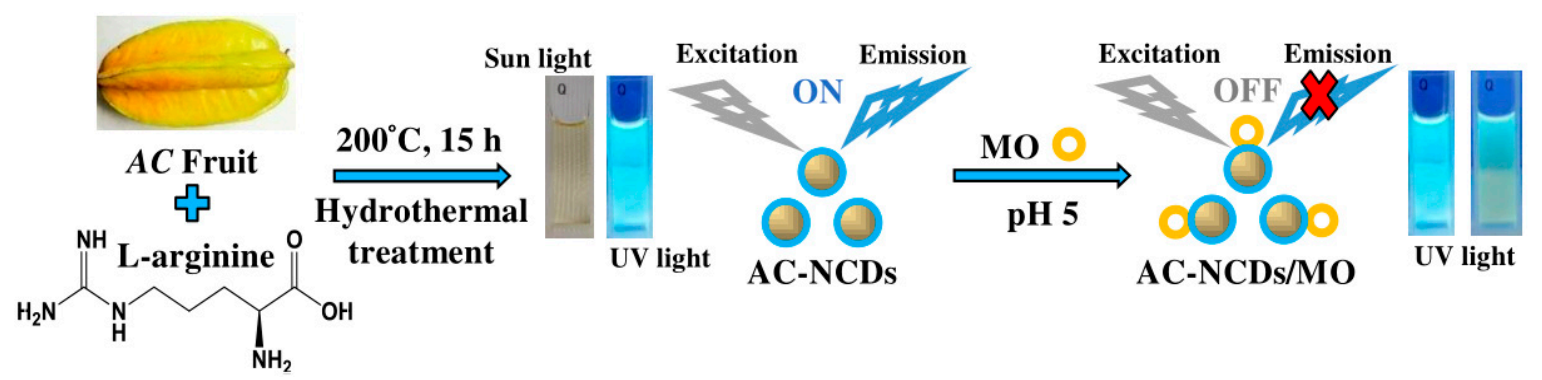

Figure 1. A schematic representation of Averrhoa carambola (AC)-nitrogen-doped carbon dots (NCDs) synthesis and application as a fluorescent probe for methyl orange (MO).

\section{Materials and Methods}

\subsection{Materials}

AC fruit was purchased from a 24h supermarket in Sanmin District, Kaohsiung City, Taiwan. Arg, alizarin (AZ), eosin B (EB), crystal violet (CV), and rose bengal (RB) were obtained from Alfa Aesar (Ward Hill, MA, USA). MO and purpurin (PP) were obtained from Sigma-Aldrich (St. Louis, MO, USA) and TCL Chemicals (Tokyo, Japan), respectively. Methylene blue (MB) was purchased from Acros Organics (Geel, Belgium). $\mathrm{NaOH}$ and $\mathrm{HCl}$ were obtained from Showa Chemical Industry Co., Ltd (Tokyo, Japan) and J.T. Baker (Phillipsburg, NJ, USA), respectively. Citrate-phosphate buffer was prepared from disodium hydrogen phosphate and citric acid anhydrous obtained from Showa Chemical Industry Co., Ltd (Tokyo, Japan). The ultrapure water from the Simplicity ${ }^{\circledR}$ Millipore Water Purification System (Burlington, VT, USA) was used as a solvent for all experiments.

\subsection{Preparation of AC Fruit Extract and AC-NCDs}

AC fruit was washed several times with ultrapure water, sliced into small pieces, and blended with a domestic blender. Subsequently, the crude extract was centrifuged $(8000 \mathrm{rpm}, 10 \mathrm{~min}$ ) to separate the pulp residues. The upper layer suspension was taken as the $\mathrm{AC}$ fruit extract and kept at $4{ }^{\circ} \mathrm{C}$ in the freezer. Afterward, AC-NCDs were synthesized by the hydrothermal treatment method. In a typical procedure, the AC fruit extract was mixed with ultrapure water (25:75, \%). $0.6 \mathrm{~g}$ Arg was added into $10 \mathrm{~mL}$ of the mixture and then transferred into hydrothermal equipment $\left(200{ }^{\circ} \mathrm{C}, 15 \mathrm{~h}\right)$ after $2 \mathrm{~min}$ sonication. Furthermore, it was allowed to cool down naturally and filtered with a Whatman filter paper to separate large residues. The solution was further purified through centrifugation $(9000 \mathrm{rpm}$, $30 \mathrm{~min}$ ) followed by filtration with a Whatman filter paper and $0.2 \mu \mathrm{M}$ PES syringe filter to dismiss residual large solid particles/starting materials and stored at $4{ }^{\circ} \mathrm{C}$ for experiments. To optimize the synthetic conditions, various solvent volume percentages, hydrothermal temperatures, hydrothermal reaction time durations, and Arg weights were evaluated.

\subsection{Characterization of AC-NCDs}

The surface morphology of AC-NCDs was characterized by using the transmission electron microscopy (TEM; Hitachi HT-7700 microscope). The functional groups of AC-NCDs were recorded by performing FTIR spectroscopy (ALPHA FTIR Spectrometer, Bruker). The UV-vis absorbance was measured by using Spectra Academy UV-Visible Spectrometer Detector SV-2100. Raman spectrum of AC-NCDs was measured by Micro Raman Identify Spectrometer from ProTrusTech Co. Ltd. (Tainan, Taiwan). The fluorescence spectra were monitored with a Varian Cary Eclipse Fluorescence Spectrophotometer. The zeta potential values were done by using a NanoPlus HD-Zeta/Nano Particle Analyzer. 


\subsection{Fluorescence Stability of AC-NCDs}

The effect of $\mathrm{pH}$ values ( $\mathrm{pH}$ 2-12) on the fluorescence behavior of AC-NCDs was adjusted with $0.1 \mathrm{mM} \mathrm{HCl}-\mathrm{NaOH}$ solutions, whereas the effect of ionic strengths was measured after adding with various $\mathrm{NaCl}$ concentrations (0-1000 mM) to AC-NCDs' solution. Besides, the light irradiation with different irradiation times (0-60 $\mathrm{min})$, storage times (1-30 days), and heating temperatures $\left(25-100{ }^{\circ} \mathrm{C}\right)$ of AC-NCDs were measured. In all cases, the fluorescence spectra were recorded with $360 \mathrm{~nm}$ excitation wavelength for comparison.

\subsection{Measurement of Fluorescence Quantum Yield}

In brief, $0.1 \mathrm{M}$ sulfuric acid was used to dilute quinine as a reference (quantum yield $(\mathrm{QY})=$ $54 \%, \eta=1.33)$, while ultrapure water $(\eta=1.33)$ was used to dilute AC-NCDs. The absorbance value at $360 \mathrm{~nm}$ was kept below 0.1 and the fluorescence spectrum with $360 \mathrm{~nm}$ excitation was recorded. The integrated fluorescence intensity and absorption value of AC-NCDs were compared to the quinine solution by using a formula:

$$
Q Y_{\mathrm{A}}=Q Y_{\mathrm{B}}\left(A_{\mathrm{B}} / A_{\mathrm{A}}\right)\left(I_{\mathrm{A}} / I_{\mathrm{B}}\right)\left(\eta_{\mathrm{A}}{ }^{2} / \eta_{\mathrm{B}}{ }^{2}\right),
$$

where, the " $Q Y$ " points to the quantum yield, " $A$ " points to the absorbance, " $I$ " points to integrated fluorescence intensity, and " $\eta$ " points to the refractive index of solvents. The " $\mathbf{A}$ " and "B" subscripts point to AC-NCDs and quinine solution, respectively.

\subsection{Fluorescent Probe for $\mathrm{MO}$}

The interaction between $\mathrm{AC}-\mathrm{NCD}$ and $\mathrm{MO}$ was measured at room temperature. For selective probe, AC-NCDs' solution (60-fold, $900 \mu \mathrm{L}, \mathrm{pH} 5.0$ with citrate-phosphate buffer) and each OD $(100 \mu \mathrm{L}, 50 \mu \mathrm{M})$ were sequentially added into $1500 \mu \mathrm{L}$ Eppendorf tubes. We performed $3 \mathrm{~min}$ of interaction time ( $1 \mathrm{~min}$ of mixing time, 2 min of incubation time) before measuring with a fluorescence spectrophotometer. The fluorescence spectra were measured at $360 \mathrm{~nm}$ excitation wavelength. For the sensitive probe, various concentrations of MO solution $(100 \mu \mathrm{L})$ were added into AC-NCDs' solution (60-fold, $900 \mu \mathrm{L}$ ). The fluorescence behavior of the AC-NDs/MO system was recorded at $360 \mathrm{~nm}$ excitation wavelength. The fluorescence behavior of the AC-NCDs/MO system under different $\mathrm{pH}$ values was also measured.

\subsection{Probing of MO in Tap Water Samples}

The applicability of AC-NCDs as a fluorescent probe for MO in real water samples was also evaluated. The tap water was utilized without any filtration or purification. The samples were spiked with the standard MO solution and added to the AC-NCDs' solution to a final concentration of 5-75 $\mu \mathrm{M}$. The fluorescence spectra of the samples were measured. To obtain the recovery percentages, the below formula was used:

$$
R=\left[\left(C_{c}-C_{b}\right) / C_{a}\right] \times 100 \%,
$$

where, " $R$ " is the recovery percentage, " $C_{a}$ " is the added MO concentration, " $C_{b}$ " is the real MO concentration without adding the standard $\mathrm{MO}$, and " $C_{c}$ " is the found $\mathrm{MO}$ concentration after adding standard MO [22].

\section{Results and Discussion}

\subsection{Optimal Synthetic Conditions of AC-NCDs}

To reach a high fluorescence property, different synthetic conditions including solvent volume percentages, hydrothermal temperatures, hydrothermal reaction time durations, and N-dopant weights were evaluated by comparing their fluorescence emission spectra. As for the percentages of solvent 
volume, the emission intensity was lower without adding ultrapure water to AC extract in the hydrothermal reaction process, while the emission intensity increased after adding different volume percentages of the solvent. The highest emission intensity was obtained with $75 \%$ of the solvent mixed with the AC fruit extract (Figure S1a). This result may be due to the chemical constituents in the AC fruit extract reacted slowly at a low solvent volume percentage. Furthermore, the temperature and reaction time duration of hydrothermal treatment possess significant effects on the fluorescence nature of CDs [23]. The AC-NCDs exhibited the highest emission intensity with a higher hydrothermal temperature and longer reaction time duration as depicted in Figure S1b,c. The emission intensity of AC-NCDs reached optimum intensity with the synthetic conditions of $15 \mathrm{~h}$ and $200{ }^{\circ} \mathrm{C}$. The increase of temperature and the prolongation of hydrothermal reaction time duration can generate more carbon nucleus, exhibiting the increase of fluorescence properties. A lower hydrothermal temperature and shorter reaction time duration are inadequate conditions for the carbonization process, thus leading a lower emission intensity [24].

Furthermore, Arg weights added to the AC fruit extract solution were also checked (Figure S1d). The emission intensity of AC-NCDs was weak with a lower Arg weight $(0.025 \mathrm{~g})$. This result may be due to the small portion of $\mathrm{N}$-source doped on the CDs. When the Arg weight was increased to $0.6 \mathrm{~g}$, then the emission intensity increased and remained constant with $0.8 \mathrm{~g}$ Arg. The strong fluorescence properties of AC-NCDs may be generated from the emissive traps of the N-containing functional groups [25]. Therefore, the optimized hydrothermal synthetic conditions were $75 \%$ of solvent volume percentage, $200{ }^{\circ} \mathrm{C}$ of temperature, $15 \mathrm{~h}$ of reaction time duration, and $0.6 \mathrm{~g}$ of $\mathrm{Arg}$ weight. The appearances of synthetic products with $0.1 \mathrm{~g}$ Arg only (1, colorless), AC fruit extract solution only (2, bright brown), and AC fruit extract solution with different Arg weights (3-9, brown to dark brown) were shown in Figure S1e. The dark brown color indicated the highest production of AC-NCDs with the highest fluorescence properties. The emission intensity comparison of CDs from $\mathrm{AC}$ fruit extract solution, $0.1 \mathrm{~g}$ Arg, and AC fruit extract solution with $0.1 \mathrm{~g}$ Arg synthesized with the same hydrothermal conditions was displayed in Figure S2. The emission intensity of CDs was increased by the passivation of Arg as N-dopant to CDs.

The formation mechanism of AC-NCDs is related to hydrothermal treatment conditions. The possible formation mechanism of AC-NCDs was illustrated in Figure 2. Several processes were involved in the formation of AC-NCDs during hydrothermal treatment including dehydration, polymerization, carbonization, and passivation [26-29]. Firstly, the $-\mathrm{COOH},-\mathrm{C}=\mathrm{O},-\mathrm{OH}$, and $-\mathrm{NH}_{2}$ groups presenting in AC fruit extract and Arg may react together, facilitating dehydration and carbonization process in elevated temperature. The continuous intermolecular dehydrationhappened during the hydrothermal process, inducing the shrinkage of polymer nanoparticles. The aromatic clusters were simultaneously produced inside the polymers and some $\mathrm{C}=\mathrm{C}$ and $\mathrm{C}=\mathrm{N}$ bonds form at this stage. The dehydration and polymerization will occur between the molecules through a well-known amidation reaction. Then, $\mathrm{O}$ atoms were substituted by $\mathrm{N}$ atoms to form amides inducing a newly formed surface state. A burst in the nucleation of NCDs takes place when the aromatic cluster concentration in the polymers reaches the critical supersaturation point. The resulting peptide chains were further carbonized with increasing NCDs particles through prolonged reaction time and then the polymeric fragments vanished. In the hydrothermal process, the surface passivation facilitates a high radiative recombination yield. As a result, a higher $\mathrm{N}$ content can increase the fluorescence $\mathrm{QY}$ and emission intensity of the CDs. 


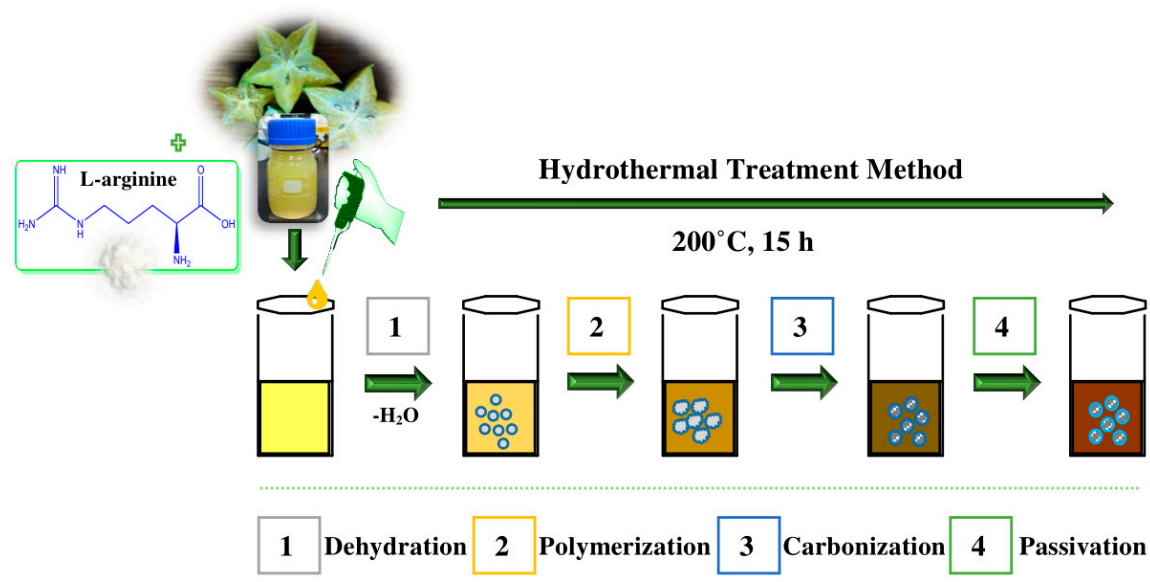

Figure 2. A proposed formation mechanism of AC-NCDs.

\subsection{Characterizations of $A C-N C D s$}

The surface morphology of AC-NCDs was captured by a TEM microscope. The TEM image of AC-NCDs with spherical shape and evenly distributed over the carbon-coated $\mathrm{Cu}$ grid was shown in Figure 3a. The size distribution of AC-NCDs was ranging from 4 to 9 with an average size of $6.67 \mathrm{~nm}$. Besides, the Raman spectrum of AC-NCDs (Figure 3b) showed the disordered D band at $\sim 1351 \mathrm{~cm}^{-1}$ and the crystalline $\mathrm{G}$ band at $\sim 1554 \mathrm{~cm}^{-1}$ associated with the $\mathrm{sp}^{3}$ - and $\mathrm{sp}^{2}$-carbon moieties in the AC-NCDs, respectively. The relative band intensity ratio $\left(I_{D} / I_{G}\right)$ is a key parameter to predict the graphitization degree of carbon nanomaterials [30]. The $I_{D} / I_{G}$ value of AC-NCDs was found to be 1.6 (in general, $I_{D} / I_{G}$ is higher than 1 for well amorphous carbon), which indicates a low degree of graphitic order, sufficient major surface defects, and plenty of surface functional groups [31]. A high degree of defect formed by nitrogenation and oxygenation processes during synthesis partially destroys the graphitic structure of AC-NCDs [32,33]. Therefore, this Raman spectrum proved that the AC-NCDs have an amorphous structure and not graphene quantum dots.
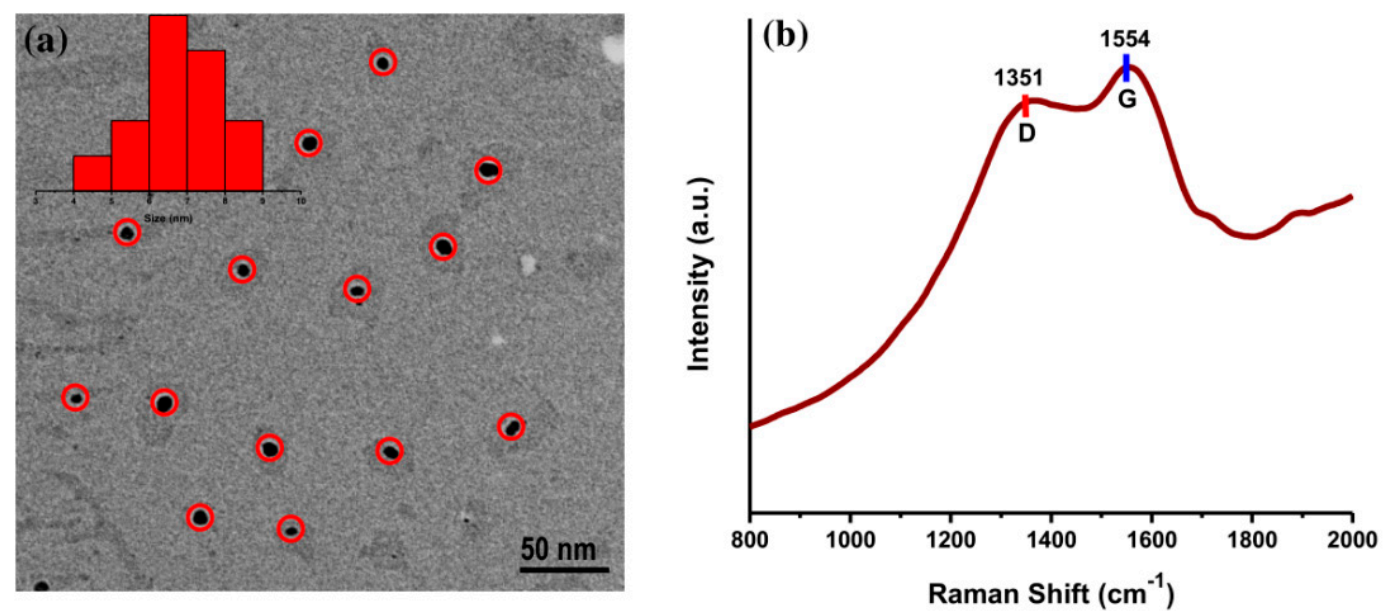

Figure 3. (a) Transmission electron microscopy (TEM) image and (b) Raman spectrum of AC-NCDs.

Furthermore, the functional groups of CDs were measured by FTIR spectroscopy. The FTIR spectra of AC-CDs (dark red line) and AC-NCDs (green line) were given in Figure 4. The FTIR spectrum of AC-CDs exhibited absorption bands at 3370, 2944, 1705, 1599, and $1397 \mathrm{~cm}^{-1}$, which conforms to the $\mathrm{O}-\mathrm{H}, \mathrm{C}-\mathrm{H}, \mathrm{C}=\mathrm{O}, \mathrm{C}=\mathrm{C}$, and $-\mathrm{COOH}$ stretching vibrations, respectively $[22,34,35]$. AC-CDs also exhibited the stretching vibration bands at $1210 / 1118$ and $643 \mathrm{~cm}^{-1}$, corresponding to $\mathrm{C}-\mathrm{O}-\mathrm{C}$ and $\mathrm{C}-\mathrm{H}$ bonds, respectively $[36,37]$. These functional groups were slightly shifted, decreased, and broadened in the FTIR spectrum of AC-NCDs due to the influence of carbonyl groups [37]. In the FTIR 
spectrum of AC-NCDs, the O-H stretching vibrations broadened ranging from 3600 to $3100 \mathrm{~cm}^{-1}$, which reveals that the $\mathrm{CDs}$ were doped by $\mathrm{N}$-dopant from Arg [38]. The stretching vibrations of $\mathrm{C}-\mathrm{H}$ groups shifted from 2944 to $2954 \mathrm{~cm}^{-1}$. The wide absorption bands of AC-NCDs centered at $1656 \mathrm{~cm}^{-1}$ were associated with $\mathrm{C}=\mathrm{O} / \mathrm{C}=\mathrm{C}$ bonds $[39,40]$. The bands at 2170 and $1004 \mathrm{~cm}^{-1}$ were correlated to the stretching vibrations of $\mathrm{C}=\mathrm{N}$ and $\mathrm{C}-\mathrm{O}$ bonds, respectively $[41,42]$. The stretching vibrations of $-\mathrm{COOH}$ groups shifted from 1397 to $1405 \mathrm{~cm}^{-1}$. The band at $1110 \mathrm{~cm}^{-1}$ was identified as $\mathrm{C}-\mathrm{N}$ and $\mathrm{C}-\mathrm{O}-\mathrm{C}$ stretching vibrations [38]. The other peaks at 775 and $663 \mathrm{~cm}^{-1}$ were identified as $\mathrm{O}-\mathrm{H}$ stretching/ $/ \mathrm{NH}_{2}$ wagging vibrations and $\mathrm{C}-\mathrm{H}$ stretching vibrations, respectively $[40,43]$.

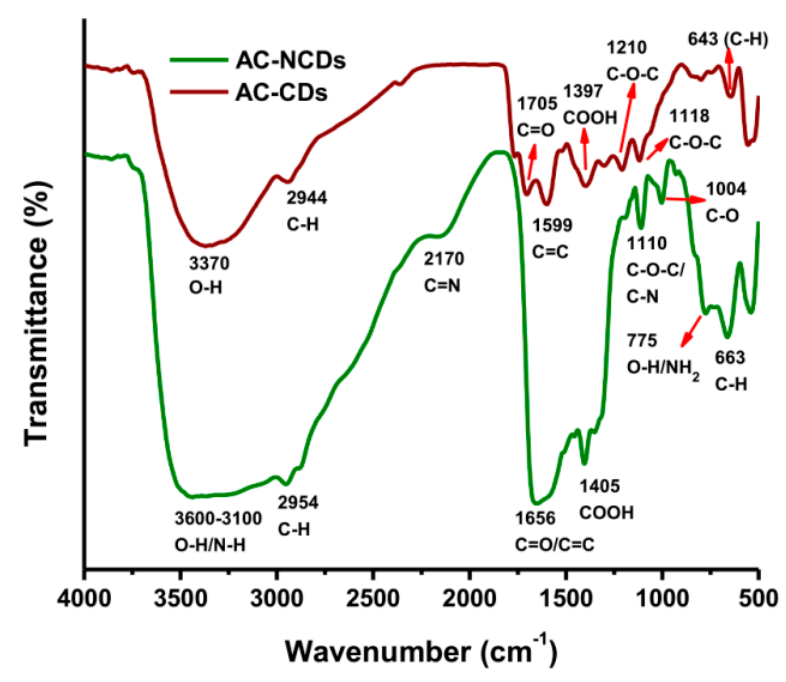

Figure 4. FTIR spectra of AC-CDs and AC-NCDs.

Moreover, to determine the electrical charges on the surface of nanoparticles and their colloidal stability, the zeta potential analysis was conducted. The zeta potential values of AC-CDs and AC-NCDs were measured and shown in Figure 5. The zeta potential value of AC-CDs was determined to be $-15.21 \mathrm{mV}$ (Figure 5a), which indicates the presence of negatively charged carboxyl (-COOH) and hydroxyl $(-\mathrm{OH})$ functional groups on their surface. The zeta potential value of AC-NCDs was determined to be $-11.88 \mathrm{mV}$ (Figure $5 \mathrm{~b}$ ). The lowering of negatively charged from $-15.21 \mathrm{mV}$ to $-11.88 \mathrm{mV}$ was due to the presence of amine $\left(-\mathrm{NH}_{2}\right)$ functional groups on the surface of AC-NCDs. This resulted in no amine groups being present on the surface of AC-CDs, making their zeta potential value more negative as a cumulative surface charge. The negative zeta potential values ensure good colloidal stability of AC-CDs and AC-NCDs.
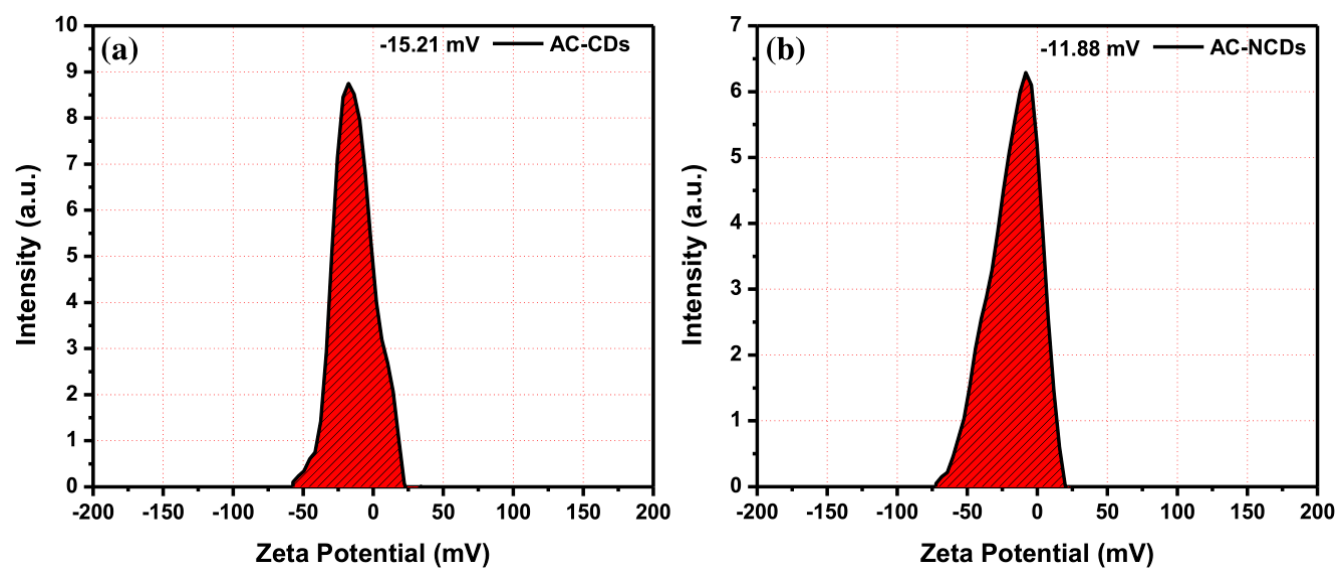

Figure 5. Zeta potential values of (a) AC-CDs and (b) AC-NCDs. 
The photograph in Figure 6a shows the color of AC-NCDs' solution with different dilution factors (0 to 100-fold) under LED-light irradiation. The strong bright blue fluorescence color was emitted from the solution under UV-light irradiation of $365 \mathrm{~nm}$ at $20 \mathrm{~W}$ power, which represents the formation of CDs (Figure 6b). AC-NCDs' solution without dilution after synthesis did not emit bright blue fluorescence color because of a very high solution concentration while AC-NCDs with 60-fold of dilution showed strong bright blue fluorescence color confirmed with the optimum fluorescence emission intensity. This latter finding indicated that the AC-NCDs possessed suitable optical properties. Figure 7a represents the UV-vis absorbance of AC-NCDs with various dilution factors. The absorption peak behaviors are proportionate to the dilutions, while the peak centers were almost unchanged. The characteristic absorption peak at $\sim 270 \mathrm{~nm}$ may be related to $\mathrm{C}=\mathrm{C}$ bonds with $\pi \rightarrow \pi^{*}$ transition [44]. The characteristic absorption peak located at $\sim 325 \mathrm{~nm}$ is typically attributed to $\mathrm{C}=\mathrm{O}$ bonds with $\mathrm{n} \rightarrow \pi^{*}$ transition [44]. The AC-NCDs exhibit strong UV absorption at the tail peak extending to the visible light region.

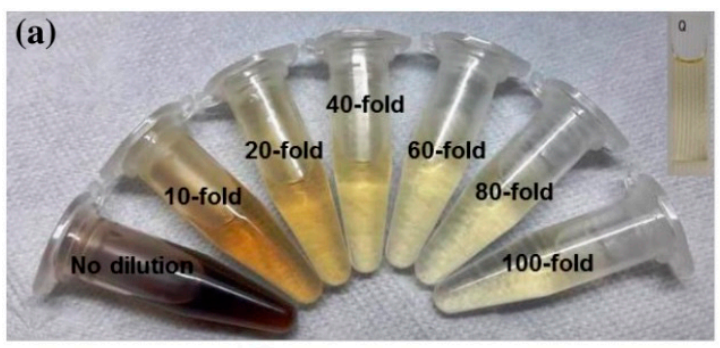

Under LED-light

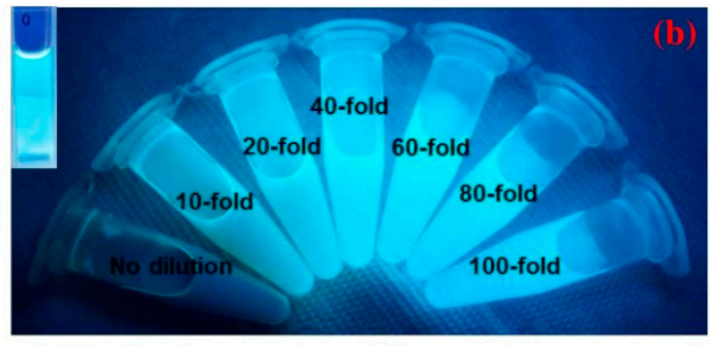

Under UV-light

Figure 6. The appearance of AC-NCDs with various dilution factors under irradiation of (a) LED-light and (b) UV-light.

(a)

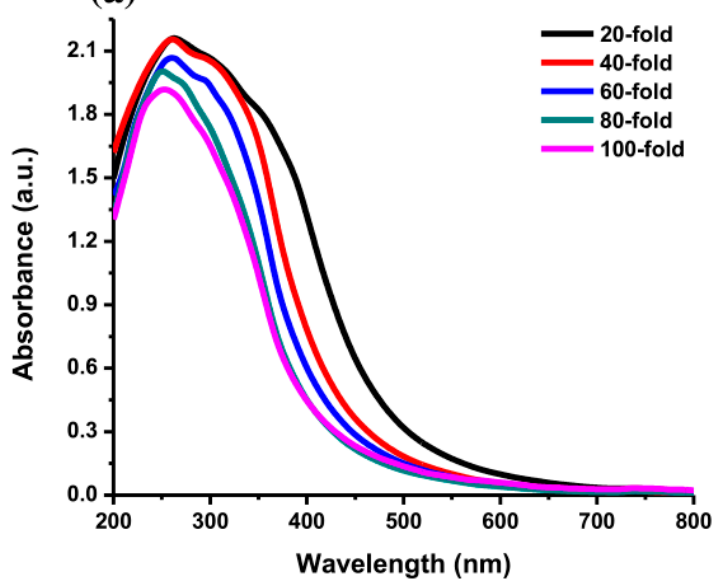

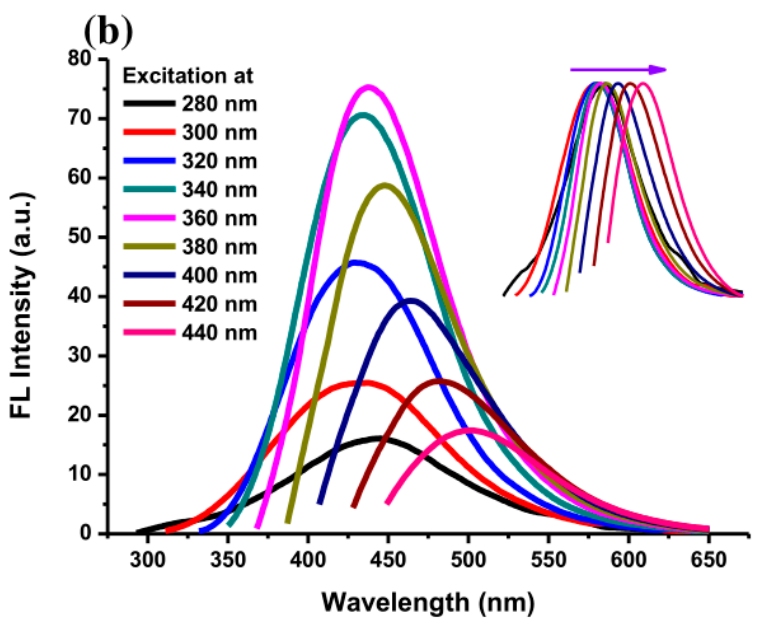

Figure 7. (a) UV-Vis absorption spectra of AC-NCDs with various dilution factors and (b) fluorescence emission spectra of AC-NCDs at excitation wavelengths of $280-440 \mathrm{~nm}$ with $20 \mathrm{~nm}$ increment (Inset: normalized fluorescence emission spectra).

Furthermore, Figure $7 \mathrm{~b}$ shows the fluorescence emission spectra of AC-NCDs with the excitation wavelengths of $280-440 \mathrm{~nm}$. The optimum emission intensity was at $446 \mathrm{~nm}$ with $360 \mathrm{~nm}$ excitation after observing all fluorescence spectra. The $446 \mathrm{~nm}$ emission wavelength was associated with the highly bright blue fluorescence color of AC-NCDs. The emission intensity increased with increasing excitation wavelength from 280 to $360 \mathrm{~nm}$ and then decreased with the increase of the excitation wavelength from 380 to $440 \mathrm{~nm}$. The clear excitation-dependent emission spectra are provided Inset Figure $7 \mathrm{~b}$. The emission peak centers red-shifted with increasing the excitation wavelengths, which may be attributed to various energy traps of AC-NCDs' surface [45]. The effect of giant red-edge is the 
cause of the strong dependency of the emission peak center with different excitation wavelengths [46]. The QY of AC-NCDs was about $12.35 \%$ determined at $360 \mathrm{~nm}$ of excitation wavelength using quinine dissolved in sulfuric acid as the reference. A higher QY may be present because of the forming of good emissive states due to the presence of N-rich groups. Table S1 shows the comparison of synthetic methods, excitation wavelengths, emission wavelengths, and QYs of several NCDs [47-51]. The AC-NCDs have higher QY compared to other reported NCDs.

\subsection{Fluorescence Stability of AC-NCDs}

The fluorescence stability of AC-NCDs was investigated to examine the potential application of AC-NCDs as a fluorescent probe. The photostability study revealed that the light irradiation had no photo-bleaching effect on the emission intensity with continuous light irradiation until $1 \mathrm{~h}$ (Figure S3a). The photo-bleaching resistant nature of nanoparticles may be due to the negatively charged functional groups of AC-NCDs have the electrostatic repulsions each other, indicating their high photostability [52]. Further, the thermal stability on the fluorescence nature was checked by heating the AC-NCDs' solution from low to high temperature $\left(25-100{ }^{\circ} \mathrm{C}\right)$ in a sealed container. There was no significant decrease in the emission intensity even at $100{ }^{\circ} \mathrm{C}$ (Figure S3b), exhibiting their high thermal stability. A higher temperature does not cause the permanent devastation of the structure and functional groups of AC-NCDs [53]. The O- and $\mathrm{N}$-functional groups may protect the nanoparticle aggregation of AC-NCDs at higher temperatures [53].

Furthermore, the effect of ionic strengths was also examined by the addition of various $\mathrm{NaCl}$ concentrations. AC-NCDs represented only a negligible decrease and a high resistance to salt concentrations up to $1000 \mathrm{mM}$, which further expands their application to identical ionic-rich environments (Figure S3c). The salt ionic strength can effectively control the aggregation of AC-NCDs and AC-NCDs particles can individually separate under salt disturbances, showing a homogeneous phase without precipitation [50]. Moreover, the shelf-life of AC-NCDs was examined by keeping them at room temperature. After storing for 30 days, no significant alterations were monitored in the emission intensity, indicating their high stability and longer shelf-life (Figure S3d). The AC-NCDs' solution shows a homogeneous phase in the long-term without clear precipitation.

Also, fluorescence measurements of AC-NCDs were performed with various $\mathrm{pH}$ values by adapting the $\mathrm{pH}$ values with $\mathrm{NaOH}$ and $\mathrm{HCl}$ solutions $(0.1 \mathrm{M})$. It can be observed that the fluorescence emission intensity changed by changing the $\mathrm{pH}$ value and the highest emission intensity was obtained with $\mathrm{pH} 5$ (Figure S3e). The $\mathrm{pH} 2$ decreased the emission intensity because of the saturated protonation of AC-NCDs in a strong acid condition [54]. The increase of emission intensity was observed after increasing the $\mathrm{pH}$ value from 2 to 5 , and then the emission intensity decreased gradually by shifting the $\mathrm{pH}$ value from 5 to 12 . These characteristics could be associated with the distinct deprotonation degrees of AC-NCDs at various $\mathrm{pH}$ values [55]. The AC-NCDs have $\mathrm{pH}$-dependent fluorescent nature because they serve as electron donors or acceptors. $\mathrm{H}^{+}$or $\mathrm{OH}^{-}$ions may prevent the electron transfer process which induces the significant change of functional groups [56]. The AC-NCDs show a good fluorescent character in a weak acid condition, while the comparatively low fluorescent characters were shown in strong acid, neutral and alkaline conditions.

\subsection{Fluorescent Probe of $M O$}

The selectivity of AC-NCDs for several ODs was evaluated at $\mathrm{pH} 5$. Figure 8a showed fluorescence spectra of AC-NCDs after adding with several ODs including PP, MB, AZ, CV, RB, EB, and MO (50 $\mu \mathrm{M})$. The fluorescence emission peak of AC-NCDs was centered on a specific wavelength after interacting with the ODs. The emission peak center of AC-NCDs at $446 \mathrm{~nm}$ was maintained after interacting with PP, MB, AZ, and RB. The emission peak center of AC-NCDs was shifted from $446 \mathrm{~nm}$ to $444 \mathrm{~nm}$, $441 \mathrm{~nm}$, and $440 \mathrm{~nm}$ after interacting with $\mathrm{EB}, \mathrm{CV}$, and $\mathrm{MO}$, respectively. The largest shift of emission peak center was occurred by MO. Therefore, this characteristic is also one of the marks for the MO interaction to AC-NCDs. Almost all ODs quenched the fluorescence intensity of AC-NCDs with 
different quenching percentages. Figure $8 \mathrm{~b}$ shows the fluorescence quenching efficiency for $\mathrm{MO}(47 \%)$ which is higher than EB (32\%), RB (24\%), CV(19\%), AZ (10\%), MB (8\%), and PP (7\%), leading to the highest selectivity of AC-NCDs for MO. The individual fluorescence emission peak of ODs without interacting with AC-NCDs was also recorded at the excitation wavelength of $360 \mathrm{~nm}$ (Figure 8c). As compared to other ODs, only MB, EB, and RB showed their very weak emission peaks with the emission wavelength of 550, 545, and $470 \mathrm{~nm}$, respectively. Because of very weak emission peaks derived from $\mathrm{MB}, \mathrm{EB}$, and $\mathrm{RB}$, and no emission peaks derived from $\mathrm{PP}, \mathrm{CV}, \mathrm{AZ}$, and $\mathrm{MO}$, so that there was no other fluorescence peak showed after interacting ODs with AC-NCDs except at $440 \mathrm{~nm}$, which corresponds to AC-NCDs' character. So, the fluorescence quenching of AC-NCDs after interacting with $\mathrm{MO}$ is the most important behavior for probing MO.
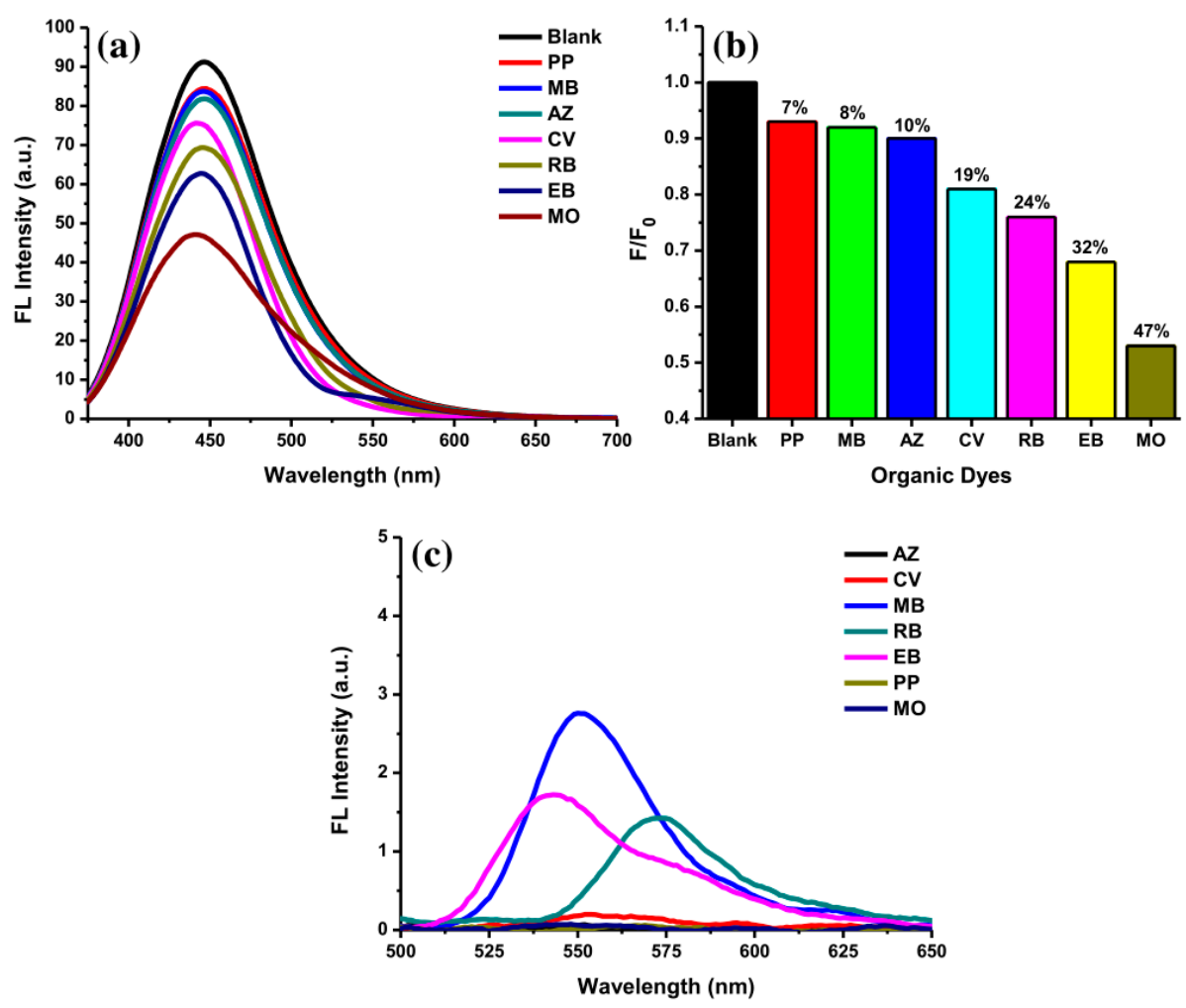

Figure 8. (a) Fluorescence emission spectra of AC-NCDs' solution with various ODs $(50 \mu \mathrm{M})$, (b) fluorescence quenching percentages of AC-NCDs' solution in the existence of various ODs, and (c) fluorescence emission spectra of ODs $(50 \mu \mathrm{M})$ at $360 \mathrm{~nm}$ excitation wavelength.

Furthermore, the interaction of AC-NCDs and MO with different concentrations was studied to explore their sensitivity on the fluorescence emission intensity. The kinetic experiments disclosed that within 3 min of interaction ( 1 min of mixing time, 2 min of incubation time), the emission intensity of AC-NCDs quenched to a fixed value which did not alter even after $30 \mathrm{~min}$ (Figure 9a). This result indicates that the reaction between $\mathrm{AC}-\mathrm{NCD}$ and $\mathrm{MO}$ was faster and more stable, recommending expectant applicability for rapid detection of $\mathrm{MO}$ without any tight time control. The $\mathrm{MO}$ reduced the fluorescence properties of AC-NCDs under UV-light irradiation by dimming the bright blue color as shown Inset Figure 9a. The sensitivity of AC-NCDs was assessed by measuring their fluorescence emission intensities toward various MO concentrations (1-200 $\mu \mathrm{M})$. As displayed in Figure $9 \mathrm{~b}$, the emission intensity of AC-NCDs gradually quenched with the increase of MO concentration. The gradual quenching of emission intensity exhibited a linear response, $\left(\mathrm{F}_{0} / \mathrm{F}\right)-1$, to the $\mathrm{MO}$ concentrations, where $\mathrm{F}_{0}$ and $\mathrm{F}$ refer to the fluorescence emission intensities at $446 \mathrm{~nm}$ without and with $\mathrm{MO}$ addition, respectively (Figure $9 \mathrm{c}$ ). The calibration curve of quenching efficiency depicted as $\left(\mathrm{F}_{0} / \mathrm{F}\right)-1$ with the 
MO concentrations ranging from 1 to $25 \mu \mathrm{M}$ has a good correlation coefficient $\left(R^{2}\right)$ of 0.99983 with $0.30 \mu \mathrm{M}$ detection limit as represented in Figure 9d.
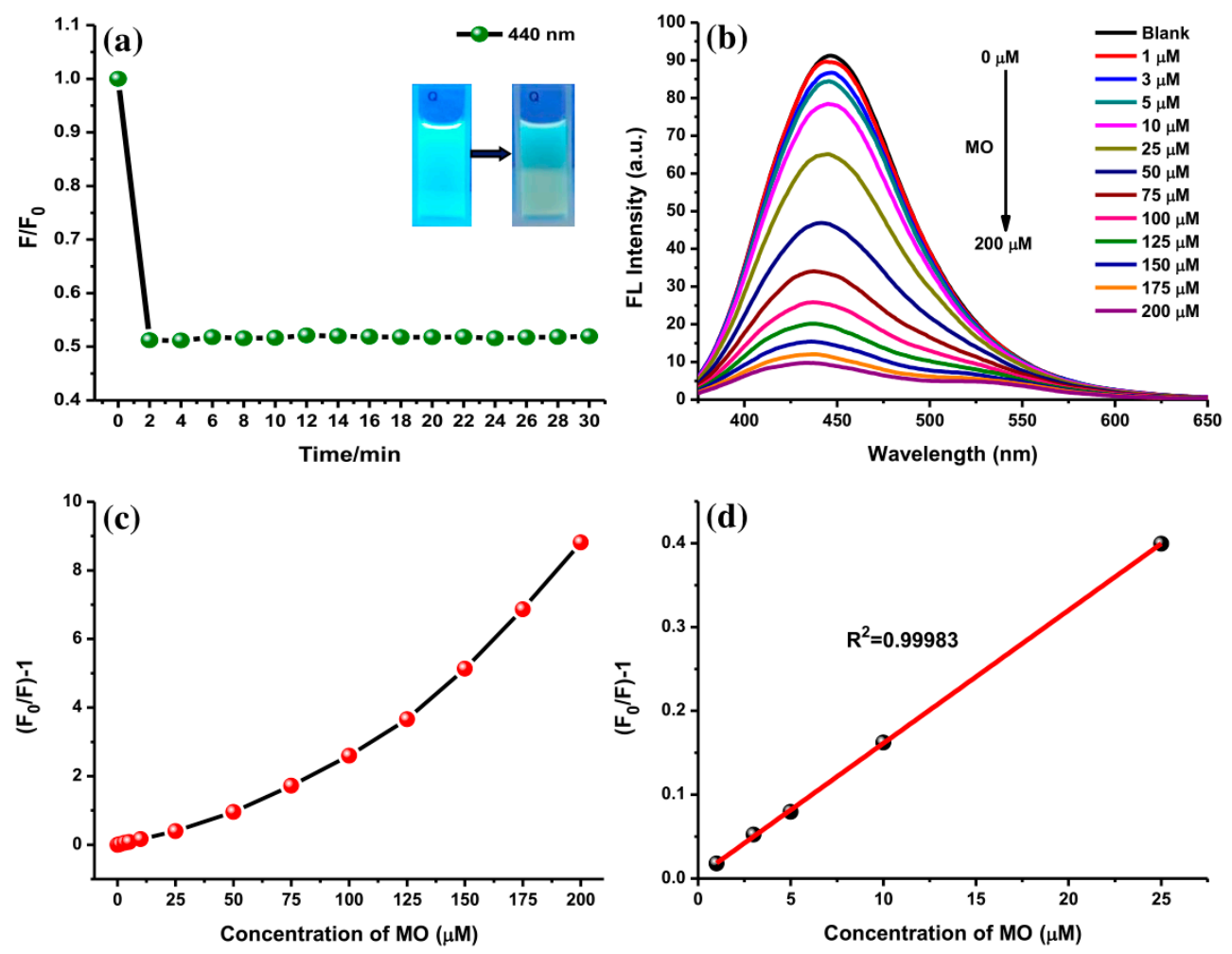

Figure 9. (a) Incubation time for the $\mathrm{AC}-\mathrm{NCD} / \mathrm{MO}$ interaction on the fluorescence behavior (Inset: AC-NCDs' and AC-NCDs/MO' solutions under UV-light irradiation), (b) fluorescence emission spectra of AC-NCDs' solution in the existence of various MO concentrations (360 $\mathrm{nm}$ excitation wavelength $360 \mathrm{~nm}, 3 \mathrm{~min}$ interaction time), (c) plots of $\left(\mathrm{F}_{0} / \mathrm{F}\right)-1$ values of AC-NCDs' solution in the presence of various $\mathrm{MO}$ concentrations $(0-200 \mu \mathrm{M})$, and (d) the relationship between the fluorescence quenching and $\mathrm{MO}$ concentrations of 1 to $25 \mu \mathrm{M}$.

In recent years, several detection methods for MO have been performed to improve the detection sensitivity. These methods include a Micellar Liquid Chromatography [18], an electrochemical sensor based on Smectite-HDTMA/GCE [19], a SERS probe based on $\beta$-CD@Ag NP monolayer [20], and an extraction by using chitosan-zinc oxide NPs [21]. In Table S2, the results of linear ranges and detection limits from the reported methods and this method for probing MO were compared. The proposed AC-NCDs' fluorescent probe offered good sensitivity with wider linearity and a relatively lower limit of detection. This method can be a preference for the MO detection in aqueous solution. Almost all of the reported methods need specific equipment, a sophisticated technique, or complex operations. Conversely, this fluorescent probe has some benefits including cheap instrumentation, easy in operation, and quick response making it more usable for routine $\mathrm{MO}$ detection in environments. The prepared AC-NCDs' solution $(10 \mathrm{~mL})$ from one-time of synthesis can be used for more than 600 times of measurements. For each measurement, only $15 \mu \mathrm{L}$ of AC-NCDs' solution was required. So, this is also one of the important benefits of using AC-NCDs as a fluorescent probe.

To further assess the applicability and feasibility of this method, the AC-NCDs as a fluorescent probe was utilized to determine the $\mathrm{MO}$ trace level in tap water samples. Because no MO was detected in the tap water samples, the samples were separately spiked with five MO concentration levels and the quantification results are summarized in Table S3. Three measurements were carried out for each concentration. The recovery measurements were carried out to assess the method's accuracy. It can be seen that the recovery results of MO in these spiked samples were in the range of 99.27 to $99.79 \%$ with 
$<1 \%$ RSDs. The MO concentrations determined by the AC-NCDs' fluorescent probe are very close to the concentrations obtained in ultrapure water. This evidence reveals the applicability of the proposed fluorescent probe for accurate detection of $\mathrm{MO}$ in real water samples. Therefore, the results confirmed that the AC-NCDs with their accuracy, sensitivity, and reliability can be potentially utilized to detect $\mathrm{MO}$ in environmental water samples.

\subsection{The $p H$ Effect on Interaction and Quenching Mechanisms}

The $\mathrm{pH}$ values present a significant role in the interaction process, influencing not only the surface charge of AC-NCDs and dissociation of surface functional groups of AC-NCDs but also the chemical speciation of $\mathrm{MO}$ molecules [57]. The effect of $\mathrm{pH}$ values from 2 to 12 on the interaction of AC-NCDs and MO to investigate further quenching efficiency was shown in Figure 10. The optimal interaction was achieved at $\mathrm{pH} 5$ due to the highest quenching efficiency of AC-NCDs after interacting with MO due to electrostatic interaction [58]. The lower interaction of AC-NCDs and MO was because of $\mathrm{H}^{+}$and $\mathrm{OH}^{-}$interruptions in strong acid and alkaline conditions. MO has two different chemical structures with quinone or azo bond chromophores, depending on the solution $\mathrm{pH}$ [59]. MO occurs as a quinone form in acid conditions and converts into an azo structure in alkaline conditions [60]. The MO quinone form has two major active positions, $-\mathrm{S}=\mathrm{O}$ and $-\mathrm{NH}$ - groups. The surface of AC-NCDs has low positive or low negative charge under acidic conditions (Figure S4), increasing the electrostatic interaction to the $-\mathrm{S}=\mathrm{O}$ groups and/or to the $-\mathrm{NH}$ - groups of $\mathrm{MO}$. In the $-\mathrm{S}=\mathrm{O}$ groups the hydrogen bonding acceptor interacts with -OH groups on the surface of AC-NCDs, while in the -NH- groups of $\mathrm{MO}$ the hydrogen bonding donor interacts with the $-\mathrm{COOH}$ groups or $-\mathrm{NH}_{2}$ groups on $\mathrm{AC}-\mathrm{NCDs}$. Besides, $\pi-\pi$ interactions between $\mathrm{C}=\mathrm{C}$ or benzene rings of $\mathrm{MO}$ in both azo and quinone type structures and bulk $\pi$-systems of AC-NCDs also play a slight role in the interaction [61]. A schematic of the plausible interactions between AC-NCDs and MO is illustrated in Figure 11.

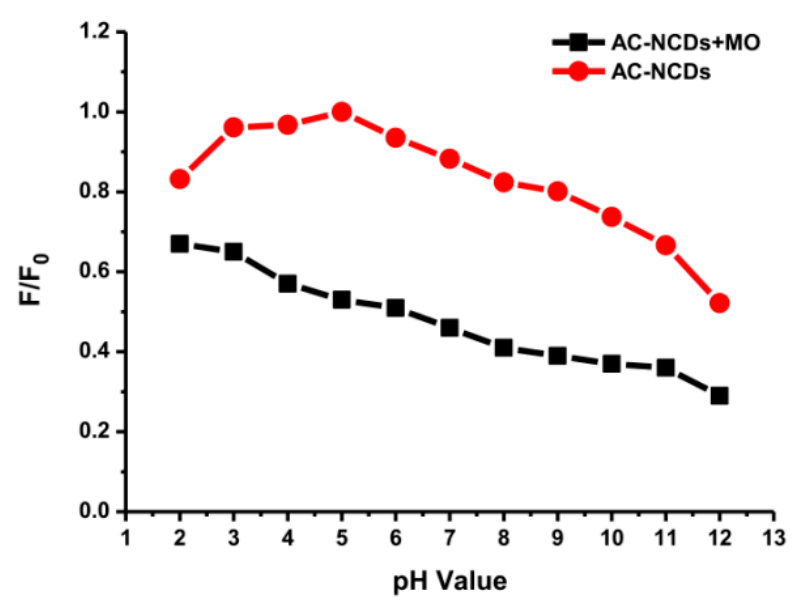

Figure 10. Fluorescence intensity of AC-NCDs and AC-NCDs/MO system with different $\mathrm{pH}$ values.

The interaction of AC-NCDs and MO was reduced significantly at the $\mathrm{pH}$ value lower than 5 which may result from slow interaction in strong acid conditions with excess $\mathrm{H}^{+}$ions, which interrupt the electron transfer from AC-NCDs to MO. The interaction between AC-NCDs and MO increased significantly at $\mathrm{pH} 5$ and slightly reduced to $\mathrm{pH}$ 9. It can be illustrated that the quenching efficiency increased obviously with the increase of $\mathrm{pH}$ ranging from $\mathrm{pH} 2$ to $\mathrm{pH} 5$ (16\% to $47 \%$ ) and slightly decrease to $\mathrm{pH} 9(41 \%)$ and decrease further to $\mathrm{pH} 12(23 \%)$. The increase of solution $\mathrm{pH}$ value provides that the AC-NCDs' surface has a higher negative charge and electrostatic repulsion with MO, resulting in a decreased percentage of their interaction. The excess of $\mathrm{OH}^{-}$ions in strongly alkaline conditions contributes to the surface charge of AC-NCDs which showed a higher negative zeta potential value (Figure S4). Also, the MO azo form has only one main active position, $-\mathrm{S}=\mathrm{O}$ groups. As a result, the fewer amount of hydrogen bonding is formed when $\mathrm{MO}$ is shifted from quinone form to azo 
form, which results in a decrease of interaction capacity [62]. Therefore, the fluorescent probe can be performed in the $\mathrm{pH}$ range from 5 to 9 where the fluorescence quenching efficiency is still in a tolerable range " $47 \%-41 \%$ ". Considering its superior detection performance, $\mathrm{pH} 5$ was the most suitable and, therefore, would be used as an expectant $\mathrm{pH}$ value for the streamlined detection of $\mathrm{MO}$ because of higher fluorescence emission intensity of AC-NCDs and higher interaction with $\mathrm{MO}$ at this $\mathrm{pH}$ value.

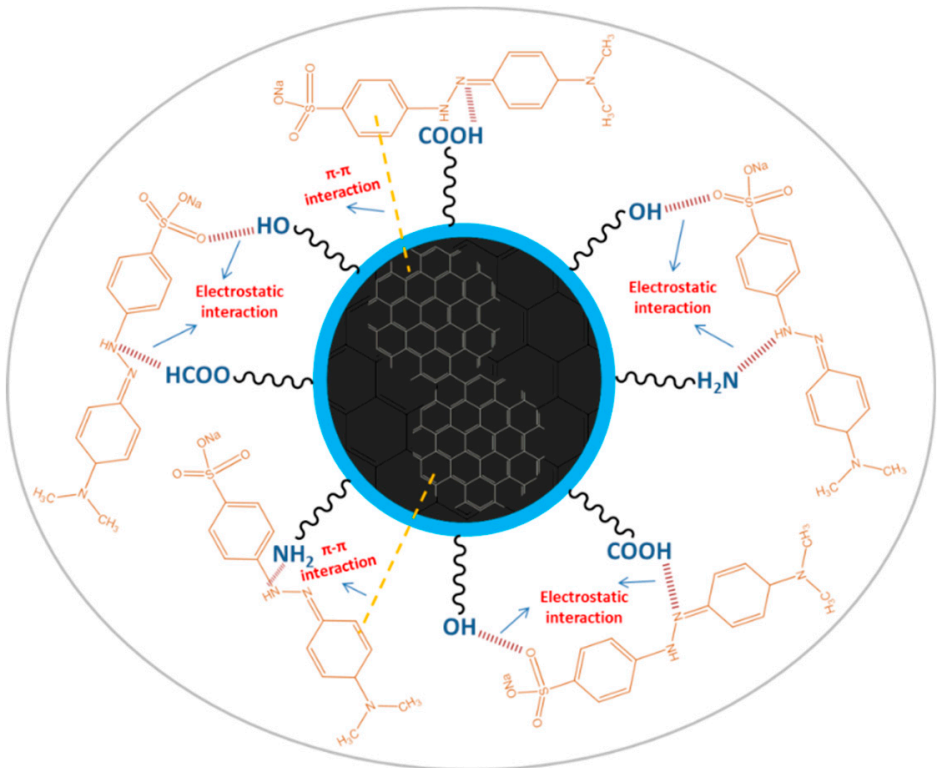

Figure 11. A schematic illustration representing plausible interactions between the AC-NCDs and MO.

Other possible quenching mechanisms were investigated by comparing the absorbance of MO and the fluorescence emission peak of AC-NCDs. As depicted in Figure S5a, MO showed two UV-vis absorption peaks at $270 \mathrm{~nm}$ and $460 \mathrm{~nm}$ while the AC-NCDs exhibited the highest emission intensity at $446 \mathrm{~nm}$. Because a great spectral overlap between the emission wavelength of the fluorescent agent/excited electrons (AC-NCDs-energy donor) and the absorption spectrum of the quencher/electron-deficient molecules (MO-energy acceptor) is necessary for the inner filter effect (IFE) and energy transfer, so the fluorescence quenching of AC-NCDs is possibly due to the IFE and energy transfer (Figure S5a) $[63,64]$. The IFE happens upon the absorption of emitted light by the absorber. Thus, the IFE and energy transfer efficiency depends on the spectral overlap between the absorber (energy acceptor) and emitter (energy transfer). According to energy transfer efficiency equation, $\mathrm{E}=1-\left(\mathrm{F}_{\mathrm{D}} / \mathrm{F}_{\mathrm{D}}{ }^{\prime}\right)[65]$ ( where $\mathrm{E}=$ energy transfer efficiency of the system, $\mathrm{F}_{\mathrm{D}}=$ the integrated fluorescence intensity of the donor with the presence of acceptor, $\mathrm{F}_{\mathrm{D}}{ }^{\prime}=$ the integrated fluorescence intensity of the donor with the absence of acceptor), the maximum energy transfer efficiency was calculated to be $44.0 \%$ for $50 \mu \mathrm{M}$ MO (Figure S6a) and $66.8 \%$ for $100 \mu \mathrm{M} \mathrm{MO}$ (Figure S6b). To achieve the $\mathrm{pH}$-dependent effect of MO on AC-NCDs, the UV-vis absorption of the AC-NCDs/MO system at various $\mathrm{pH}$ values was evaluated. The increasing of fluorescence quenching efficiency could be related to the MO-induced alterations of the absorption peak. As represented in Figure S5b, the MO absorbance at $460 \mathrm{~nm}$ slightly reduced when the AC-NCDs/MO system at $\mathrm{pH} 5$; thus, the quenching efficiency of AC-NCDs was higher than $\mathrm{pH} 12$ with additional lower absorbance at $460 \mathrm{~nm}$. The quenching efficiency of the AC-NCDs/MO system at $\mathrm{pH} 5$ and $\mathrm{pH} 12$ was still higher than that at $\mathrm{pH} 2$ as confirmed with the fluorescence quenching percentages. From the normalized absorption spectra, these $\mathrm{pH}$ values (5 and 12) produced the spectral overlaps between the absorption peak of $\mathrm{MO}$ and the emission spectrum of AC-NCDs. The spectral overlap reduction appeared at $\mathrm{pH} 2$ by shifting the wavelength from $460 \mathrm{~nm}$ to $505 \mathrm{~nm}$ with changing its color from yellow to red as shown in Figure S7, indicating the quenching reduction based on the decrease of IFE and energy transfer effects. The results denoted that the IFE and energy transfer efficiency of AC-NCDs by MO was $\mathrm{pH}$-dependence. 


\section{Conclusions}

A rapid and facile fluorescent probe-based on AC-NCDs was successfully utilized for MO detection. The AC-NCDs were prepared through a simple and green hydrothermal treatment method using A. carambola fruit extract and Arg as a carbon precursor and a nitrogen dopant for the first time, respectively. The AC-NCDs were spherical with $6.67 \mathrm{~nm}$ of average size. The optimum fluorescence emission intensity was centered at $446 \mathrm{~nm}$ with $360 \mathrm{~nm}$ excitation wavelength. The fluorescent quantum yield was calculated to be $12.35 \%$. The AC-NCDs were used as a fluorescent probe for MO with higher selectivity and sensitivity. The quenching percentages were affected by the $\mathrm{pH}$ values of the system. The plausible interaction mechanisms were driven by electrostatic interaction, $\pi-\pi$ interaction, inner filter effect, and energy transfer. Under optimum conditions, the calibration curve of the fluorescent probe was linear from 1 to $25 \mu \mathrm{M}$ range with $\mathrm{R}^{2}$ of 0.99983 and a $0.30 \mu \mathrm{M}$ detection limit. This work provides a potential application of AC-NCDs to detect MO for environmental protection.

Supplementary Materials: The following data are available online at http://www.mdpi.com/1424-8220/19/22/ 5008/s1, Figure S1: Fluorescence intensity of AC-NCDs prepared at different (a) solvent volume percentages, (b) hydrothermal temperatures, (c) reaction time durations, (d) weights of Arg in $10 \mathrm{~mL}$ AC fruit extract solutions, and (e) the appearances of synthetic products (1: $0.1 \mathrm{~g} \mathrm{~L}$-arginine only in $10 \mathrm{~mL} \mathrm{H}_{2} \mathrm{O}, 2$ : AC fruit extract solution only, 3-9: AC fruit extract solution with L-arginine $(0.025,0.05,0.1,0.2,0.4,0.6,0.8 \mathrm{~g}$, respectively)). Synthetic conditions were kept at $200{ }^{\circ} \mathrm{C}$ of temperature and $15 \mathrm{~h}$ of reaction time duration, Figure S2: Fluorescence intensity of (a) CDs from AC fruit extract solution, (b) CDs from $0.1 \mathrm{~g}$ Arg in $10 \mathrm{~mL}$ ultrapure water, and (c) AC-NCDs prepared from AC fruit extract solution with $0.1 \mathrm{~g}$ Arg. The excitation wavelength was $360 \mathrm{~nm}$ and the synthetic conditions were kept at $200{ }^{\circ} \mathrm{C}$ for $15 \mathrm{~h}$, Figure S3: The fluorescence spectra comparison of AC-NCDs' solution with various (a) light irradiation times, (b) heating temperatures, (c) salt concentrations, (d) storage times, and (e) $\mathrm{pH}$ values, Figure S4: Zeta potential graphs of AC-NCDs' solutions at different pH values $(2,5,9$, and 12), Figure S5: (a) The normalized fluorescence emission spectrum of AC-NCDs and UV-vis absorption spectrum of $\mathrm{MO}$, and (b) UV-vis spectra comparison of AC-NCDs, MO, and AC-NCDs/MO system ( $\mathrm{pH} 2,5$, and 12). The MO concentration was $50 \mu \mathrm{M}$, Figure S6: FRET measurement according to the equation $\mathrm{E}=1-\left(\mathrm{F}_{\mathrm{D}} / \mathrm{F}_{\mathrm{D}}{ }^{\prime}\right)$. The excitation wavelength was $360 \mathrm{~nm}$; the integrated fluorescence intensity was calculated from $360 \mathrm{~nm}$ to 650 nm with (a) $50 \mu \mathrm{M}$ MO and (b) $100 \mu \mathrm{M}$ MO, Figure S7: The appearance of AC-NCDs/MO' solution with different $\mathrm{pH}$ values (MO concentration was $50 \mu \mathrm{M}$ ), Table S1: The comparison of starting materials, synthetic methods, excitation wavelengths $\left(\lambda_{\mathrm{ex}}\right)$, emission wavelengths $\left(\lambda_{\mathrm{em}}\right)$, and quantum yield (QY) from some N-doped CDs, Table S2: The comparison of this method with other methods for the probing of MO, Table S3: The probing of MO in tap water samples $(n=3)$.

Author Contributions: Conceptualization, M.Z., Y.-P.C., and G.G.H.; formal analysis, M.Z.; funding acquisition, G.G.H.; investigation, M.Z., S.D., W.-Y.L., C.-J.C., and G.G.H.; methodology, M.Z.; project administration, G.G.H.; resources, G.G.H.; supervision, G.G.H.; writing—original draft, M.Z.; writing-review and editing, M.Z. and G.G.H.

Funding: This work was financially supported by the Taiwan Ministry of Science and Technology (MOST107-2113-M-037-013) and NSYSU-KMU Joint Research Project (\#NSYSUKMU 108-I002-3).

Acknowledgments: We thank the head of the Department of Medicinal and Applied Chemistry, Kaohsiung Medical University for providing the accessibility of instruments and other facilities.

Conflicts of Interest: The authors declare no conflict of interest.

\section{References}

1. Wang, Y.; Hu, A. Carbon quantum dots: Synthesis, properties and applications. J. Mater. Chem. C 2014, 2, 6921-6939. [CrossRef]

2. Wang, Y.; Zhu, Y.; Yu, S.; Jiang, C. Fluorescent carbon dots: Rational synthesis, tunable optical properties and analytical applications. RSC Adv. 2017, 7, 40973-40989. [CrossRef]

3. Zhang, J.; Yu, S.H. Carbon dots: Large-scale synthesis, sensing and bioimaging. Mater. Today 2016, 19, 382-393. [CrossRef]

4. Park, Y.; Yoo, J.; Lim, B.; Kwon, W.; Rhee, S.W. Improving the functionality of carbon nanodots: Doping and surface functionalization. J. Mater. Chem. A 2016, 4, 11582-11603. [CrossRef]

5. Li, L.; Dong, T. Photoluminescence tuning in carbon dots: Surface passivation or/and functionalization, heteroatom doping. J. Mater. Chem. C 2018, 6, 7944-7970. [CrossRef]

6. Zhang, X.; Jiang, M.; Niu, N.; Chen, Z.; Li, S.; Liu, S.; Li, J. Natural-Product-Derived Carbon Dots: From Natural Products to Functional Materials. ChemSusChem 2018, 11, 11-24. [CrossRef] 
7. Wang, R.; Lu, K.Q.; Tang, Z.R.; Xu, Y.J. Recent progress in carbon quantum dots: Synthesis, properties and applications in photocatalysis. J. Mater. Chem. A 2017, 5, 3717-3734. [CrossRef]

8. Shi, L.; Li, Y.; Li, X.; Wen, X.; Zhang, G.; Yang, J.; Dong, C.; Shuang, S. Facile and eco-friendly synthesis of green fluorescent carbon nanodots for applications in bioimaging, patterning and staining. Nanoscale 2015, 7, 7394-7401. [CrossRef]

9. Sharma, V.; Tiwari, P.; Mobin, S.M. Sustainable carbon-dots: Recent advances in green carbon dots for sensing and bioimaging. J. Mater. Chem. B 2017, 5, 8904-8924. [CrossRef]

10. Jia, X.; Yang, D.; Yang, Y.; Xie, H. Carotenoid-Derived Flavor Precursors from Averrhoa carambola Fresh Fruit. Molecules 2019, 24, 256. [CrossRef]

11. Saha, D.; Guite, D.J.; Das, T. A Complete Review on the Pharmacological Evaluation of Averrhoa Carambola Plant. World J. Pharm. Res. 2018, 7, 199-210.

12. Payal, G.; Pankti, K.; Manodeep, C.; Jag, K. Phytochemical and Pharmacological Profile of Averrhoa Carambola Linn: An Overview. Int. Res. J. Pharm. 2012, 3, 88-92.

13. Arcudi, F.; Dordevic, L.; Prato, M. Design, Synthesis, and Functionalization Strategies of Tailored Carbon Nanodots. Acc. Chem. Res. 2019, 52, 2070-2079. [CrossRef] [PubMed]

14. Utagawa, T. Arginine Metabolism: Enzymology, Nutrition, and Clinical Significance. J. Nutr. 2004, 134, 2854-2857. [CrossRef]

15. Naseri, A.; Barati, R.; Rasoulzadeh, F.; Bahram, M. Studies on Adsorption of Some Organic Dyes from Aqueous Solution onto Graphene Nanosheets. Iran. J. Chem. Chem. Eng. 2015, 34, 51-60.

16. Ambashta, R.D.; Sillanpää, M. Water purification using magnetic assistance: A review. J. Hazard. Mater. 2010, 180, 38-49. [CrossRef]

17. Tang, Y.; Yang, R.; Ma, D.; Zhou, B.; Zhu, L.; Yang, J. Removal of methyl orange from aqueous solution by adsorption onto a hydrogel composite. Polym. Polym. Compos. 2018, 26, 161-168. [CrossRef]

18. Ashok, V.; Agrawal, N.; Esteve-Romero, J.; Bose, D.; Dubey, N.P. Detection of Methyl Orange in Saffron and Other Edibles Using Direct Injection Micellar Liquid Chromatography. Food Anal. Methods 2017, 10, 269-276. [CrossRef]

19. Tcheumi, H.L.; Babu, B.R. Surfactant-intercalated smectite modified electrode: Sensitive electrochemical detection of methyl orange dye. Int. J. Environ. Anal. Chem. 2017, 97, 1207-1222. [CrossRef]

20. Liu, J.; Zhang, C.; Zhang, S.; Yu, H.; Xie, W. A versatile $\beta$-cyclodextrin functionalized silver nanoparticle monolayer for capture of methyl orange from complex wastewater. Chin. Chem. Lett. 2019. [CrossRef]

21. Khajeh, M.; Golzary, A.R. Synthesis of zinc oxide nanoparticles-chitosan for extraction of methyl orange from water samples: Cuckoo optimization algorithm-artificial neural network. Spectrochim. Acta-Part A Mol. Biomol. Spectrosc. 2014, 131, 189-194. [CrossRef] [PubMed]

22. Liu, W.; Diao, H.; Chang, H.; Wang, H.; Li, T.; Wei, W. Green synthesis of carbon dots from rose-heart radish and application for Fe3+ detection and cell imaging. Sens. Actuators B Chem. 2017, 241, 190-198. [CrossRef]

23. Zulfajri, M.; Gedda, G.; Chang, C.-J.; Chang, Y.-P.; Huang, G.G. Cranberry Beans Derived Carbon Dots as a Potential Fluorescence Sensor for Selective Detection of Fe3+ Ions in Aqueous Solution. ACS Omega 2019, 4, 15382-15392. [CrossRef] [PubMed]

24. Ogi, T.; Aishima, K.; Permatasari, F.A.; Iskandar, F.; Tanabe, E.; Okuyama, K. Kinetics of nitrogen-doped carbon dot formation: Via hydrothermal synthesis. New J. Chem. 2016, 40, 5555-5561. [CrossRef]

25. Zhang, R.; Chen, W. Nitrogen-doped carbon quantum dots: Facile synthesis and application as a "turn-off" fluorescent probe for detection of $\mathrm{Hg} 2+$ ions. Biosens. Bioelectron. 2013, 55, 83-90. [CrossRef] [PubMed]

26. Hu, Y.; Yang, J.; Tian, J.; Yu, J.S. How do nitrogen-doped carbon dots generate from molecular precursors? An investigation of the formation mechanism and a solution-based large-scale synthesis. J. Mater. Chem. B 2015, 3, 5608-5614. [CrossRef]

27. Sun, C.; Zhang, Y.; Wang, P.; Yang, Y.; Wang, Y.; Xu, J.; Wang, Y.; Yu, W.W. Synthesis of Nitrogen and Sulfur Co-doped Carbon Dots from Garlic for Selective Detection of Fe3+. Nanoscale Res. Lett. 2016, 11, 1-9. [CrossRef]

28. Zhu, S.; Song, Y.; Zhao, X.; Shao, J.; Zhang, J.; Yang, B. The photoluminescence mechanism in carbon dots (graphene quantum dots, carbon nanodots, and polymer dots): Current state and future perspective. Nano Res. 2015, 8, 355-381. [CrossRef] 
29. Zeng, Y.W.; Ma, D.K.; Wang, W.; Chen, J.J.; Zhou, L.; Zheng, Y.Z.; Yu, K.; Huang, S.M. N,S co-doped carbon dots with orange luminescence synthesized through polymerization and carbonization reaction of amino acids. Appl. Surf. Sci. 2015, 342, 136-143. [CrossRef]

30. Abo El Naga, A.O.; Shaban, S.A.; El Kady, F.Y.A. Metal organic framework-derived nitrogen-doped nanoporous carbon as an efficient adsorbent for methyl orange removal from aqueous solution. J. Taiwan Inst. Chem. Eng. 2018, 93, 363-373. [CrossRef]

31. Anju, M.; Divya, T.; Nikhila, M.P.; Kusumam, T.V.A.; Akhila, A.K.; Ansi, V.A.; Renuka, N.K. An elegant and handy selective sensor for ppt level determination of mercury ions. RSC Adv. 2016, 6, 109506-109513. [CrossRef]

32. Luo, Z.; Yang, D.; Yang, C.; Wu, X.; Hu, Y.; Zhang, Y.; Yuwen, L.; Yeow, E.K.L.; Weng, L.; Huang, W.; et al. Graphene quantum dots modified with adenine for efficient two-photon bioimaging and white light-activated antibacteria. Appl. Surf. Sci. 2018, 434, 155-162. [CrossRef]

33. Ramanan, V.; Subray, S.H.; Ramamurthy, P. A green synthesis of highly luminescent carbon dots from itaconic acid and their application as an efficient sensor for Fe3+ ions in aqueous medium. New J. Chem. 2018, 42, 8933-8942. [CrossRef]

34. Shen, J.; Shang, S.; Chen, X.; Wang, D.; Cai, Y. Facile synthesis of fluorescence carbon dots from sweet potato for Fe3+ sensing and cell imaging. Mater. Sci. Eng. C 2017, 76, 856-864. [CrossRef] [PubMed]

35. Li, L.S.; Jiao, X.Y.; Zhang, Y.; Cheng, C.; Huang, K.; Xu, L. Green synthesis of fluorescent carbon dots from Hongcaitai for selective detection of hypochlorite and mercuric ions and cell imaging. Sens. Actuators B Chem. 2018, 263, 426-435. [CrossRef]

36. Yang, Q.; Duan, J.; Yang, W.; Li, X.; Mo, J.; Yang, P.; Tang, Q. Nitrogen-doped carbon quantum dots from biomass via simple one-pot method and exploration of their application. Appl. Surf. Sci. 2018, 434, 1079-1085. [CrossRef]

37. Arul, V.; Sethuraman, M.G. Facile green synthesis of fluorescent N-doped carbon dots from Actinidia deliciosa and their catalytic activity and cytotoxicity applications. Opt. Mater. 2018, 78, 181-190. [CrossRef]

38. Bandi, R.; Dadigala, R.; Gangapuram, B.R.; Guttena, V. Green synthesis of highly fluorescent nitrogen-Doped carbon dots from Lantana camara berries for effective detection of lead (II) and bioimaging. J. Photochem. Photobiol. B Biol. 2018, 178, 330-338. [CrossRef]

39. Venkateswarlu, S.; Viswanath, B.; Reddy, A.S.; Yoon, M. Fungus-derived photoluminescent carbon nanodots for ultrasensitive detection of $\mathrm{Hg} 2+$ ions and photoinduced bactericidal activity. Sens. Actuators B Chem. 2018, 258, 172-183. [CrossRef]

40. Zhang, J.; Zhao, X.; Xian, M.; Dong, C.; Shuang, S. Folic acid-conjugated green luminescent carbon dots as a nanoprobe for identifying folate receptor-positive cancer cells. Talanta 2018, 183, 39-47. [CrossRef]

41. Yang, X.; Zhuo, Y.; Zhu, S.; Luo, Y.; Feng, Y.; Dou, Y. Novel and green synthesis of high-fluorescent carbon dots originated from honey for sensing and imaging. Biosens. Bioelectron. 2014, 60, 292-298. [CrossRef] [PubMed]

42. Li, J.; Zuo, G.; Qi, X.; Wei, W.; Pan, X.; Su, T.; Zhang, J.; Dong, W. Selective determination of Ag+using Salecan derived nitrogen doped carbon dots as a fluorescent probe. Mater. Sci. Eng. C 2017, 77, 508-512. [CrossRef] [PubMed]

43. Srivastava, S.; Gajbhiye, N.S. Carbogenic nanodots: Photoluminescence and room-temperature ferromagnetism. ChemPhysChem 2011, 12, 2624-2632. [CrossRef] [PubMed]

44. Jia, X.; Li, J.; Wang, E. One-pot green synthesis of optically pH-sensitive carbon dots with upconversion luminescence. Nanoscale 2012, 4, 5572-5575. [CrossRef] [PubMed]

45. Liu, Y.; Zhou, Q.; Li, J.; Lei, M.; Yan, X. Selective and sensitive chemosensor for lead ions using fluorescent carbon dots prepared from chocolate by one-step hydrothermal method. Sens. Actuators B Chem. 2016, 237, 597-604. [CrossRef]

46. Cushing, S.K.; Li, M.; Huang, F.; Wu, N. Origin of strong excitation wavelength dependent fluorescence of graphene oxide. ACS Nano 2014, 8, 1002-1013. [CrossRef]

47. Guo, L.; Li, L.; Liu, M.; Wan, Q.; Tian, J.; Huang, Q.; Wen, Y.; Liang, S.; Zhang, X.; Wei, Y. Bottom-up preparation of nitrogen doped carbon quantum dots with green emission under microwave-assisted hydrothermal treatment and their biological imaging. Mater. Sci. Eng. C 2017, 84, 60-66. [CrossRef] 
48. Iqbal, A.; Tian, Y.; Wang, X.; Gong, D.; Guo, Y.; Iqbal, K.; Wang, Z.; Liu, W.; Qin, W. Carbon dots prepared by solid state method via citric acid and 1,10-phenanthroline for selective and sensing detection of Fe2+ and Fe3+. Sens. Actuators B Chem. 2016, 237, 408-415. [CrossRef]

49. Atchudan, R.; Edison, T.N.J.I.; Chakradhar, D.; Perumal, S.; Shim, J.J.; Lee, Y.R. Facile green synthesis of nitrogen-doped carbon dots using Chionanthus retusus fruit extract and investigation of their suitability for metal ion sensing and biological applications. Sens. Actuators B Chem. 2017, 246, 497-509. [CrossRef]

50. Das, P.; Ganguly, S.; Bose, M.; Mondal, S.; Das, A.K.; Banerjee, S.; Das, N.C. A simplistic approach to green future with eco-friendly luminescent carbon dots and their application to fluorescent nano-sensor "turn-off" probe for selective sensing of copper ions. Mater. Sci. Eng. C 2017, 75, 1456-1464. [CrossRef]

51. Edison, T.N.J.I.; Atchudan, R.; Shim, J.J.; Kalimuthu, S.; Ahn, B.C.; Lee, Y.R. Turn-off fluorescence sensor for the detection of ferric ion in water using green synthesized N-doped carbon dots and its bio-imaging. J. Photochem. Photobiol. B Biol. 2016, 158, 235-242. [CrossRef] [PubMed]

52. Huang, H.; Lv, J.J.; Zhou, D.L.; Bao, N.; Xu, Y.; Wang, A.J.; Feng, J.J. One-pot green synthesis of nitrogen-doped carbon nanoparticles as fluorescent probes for mercury ions. RSC Adv. 2013, 3, 21691-21696. [CrossRef]

53. Khan, W.U.; Wang, D.; Wang, Y. Highly Green Emissive Nitrogen-Doped Carbon Dots with Excellent Thermal Stability for Bioimaging and Solid-State LED. Inorg. Chem. 2018, 57, 15229-15239. [CrossRef] [PubMed]

54. Xu, L.; Fan, H.; Huang, L.; Xia, J.; Huang, J.; Li, M.; Ding, H.; Huang, K.; Li, S. Eosinophilic nitrogen-doped carbon dots derived from tribute chrysanthemum for label-free detection of Fe3+ ions and hydrazine. J. Taiwan Inst. Chem. Eng. 2017, 78, 247-253. [CrossRef]

55. Liu, Y.; Liu, Y.; Park, S.J.; Zhang, Y.; Kim, T.; Chae, S.; Park, M.; Kim, H.Y. One-step synthesis of robust nitrogen-doped carbon dots: Acid-evoked fluorescence enhancement and their application in Fe 3+ detection. J. Mater. Chem. A 2015, 3, 17747-17754. [CrossRef]

56. Liang, Q.; Ma, W.; Shi, Y.; Li, Z.; Yang, X. Easy synthesis of highly fluorescent carbon quantum dots from gelatin and their luminescent properties and applications. Carbon 2013, 60, 421-428. [CrossRef]

57. Foo, K.Y.; Hameed, B.H. Factors affecting the carbon yield and adsorption capability of the mangosteen peel activated carbon prepared by microwave assisted K 2CO 3 activation. Chem. Eng. J. 2012, 180, 66-74. [CrossRef]

58. Huang, R.; Liu, Q.; Huo, J.; Yang, B. Adsorption of methyl orange onto protonated cross-linked chitosan. Arab. J. Chem. 2017, 10, 24-32. [CrossRef]

59. Chen, S.; Zhang, J.; Zhang, C.; Yue, Q.; Li, Y.; Li, C. Equilibrium and kinetic studies of methyl orange and methyl violet adsorption on activated carbon derived from Phragmites australis. Desalination 2010, 252, 149-156. [CrossRef]

60. Zhu, H.Y.; Jiang, R.; Xiao, L.; Zeng, G.M. Preparation, characterization, adsorption kinetics and thermodynamics of novel magnetic chitosan enwrapping nanosized $\gamma$-Fe2O3 and multi-walled carbon nanotubes with enhanced adsorption properties for methyl orange. Bioresour. Technol. 2010, 101, 5063-5069. [CrossRef]

61. Čerović, L.S.; Milonjić, S.K.; Todorović, M.B.; Trtanj, M.I.; Pogozhev, Y.S.; Blagoveschenskii, Y.; Levashov, E.A. Point of zero charge of different carbides. Colloids Surf. A Physicochem. Eng. Asp. 2007, 297, 1-6. [CrossRef]

62. Liu, X.; An, S.; Wang, Y.; Yang, Q.; Zhang, L. Rapid selective separation and recovery of a specific target dye from mixture consisted of different dyes by magnetic Ca-ferrites nanoparticles. Chem. Eng. J. 2015, 262, 517-526. [CrossRef]

63. Zu, F.; Yan, F.; Bai, Z.; Xu, J.; Wang, Y.; Huang, Y.; Zhou, X. The quenching of the fluorescence of carbon dots: A review on mechanisms and applications. Microchim. Acta 2017, 184, 1899-1914. [CrossRef]

64. Liu, H.; Xu, C.; Bai, Y.; Liu, L.; Liao, D.; Liang, J.; Liu, L.; Han, H. Interaction between fluorescein isothiocyanate and carbon dots: Inner filter effect and fluorescence resonance energy transfer. Spectrochim. Acta-Part A Mol. Biomol. Spectrosc. 2017, 171, 311-316. [CrossRef]

65. Yang, K.; Li, F.; Che, W.; Hu, X.; Liu, C.; Tian, F. Increment of the FRET efficiency between carbon dots and photosensitizers for enhanced photodynamic therapy. RSC Adv. 2016, 6, 101447-101451. [CrossRef]

(C) 2019 by the authors. Licensee MDPI, Basel, Switzerland. This article is an open access article distributed under the terms and conditions of the Creative Commons Attribution (CC BY) license (http://creativecommons.org/licenses/by/4.0/). 